\title{
La micro-región: espacio y tiempo en la cartografía producida por la interacción jesuítico-guaraní/
}

\author{
The microregion: space and time in the cartography \\ produced by the interaction jesuitical-guarani
}

\begin{abstract}
Norberto Levinton
Universidad del Salvador, Argentina

La interacción cultural entre los jesuitas y los indios guaraníes aparece subrepticiamente en muchas de las prácticas realizadas en los pueblos misioneros. En algunos temas se visualiza una adaptación relativa de los sacerdotes a la manera de ser indígena y en otros, es posible interpretar un proceso indígena de reinterpretación de sus propias costumbres anteriores al contacto. Al respecto, la cartografía relacionada con el proceso de configuración de la micro-región correspondiente a cada asentamiento, es una muestra de estos intercambios.

Palabras ClaVe: Territorio; Micro-región; Tiempo; Espacio; Simbología.

The cultural interaction between the Jesuits and the Guarani Indians appears silently in many of the practices realized in the missionary villages. In some topics a relative adjustment of the priests is visualized like being an Indian custom and in others, is a possible to interpret a process indigenous to reintepretation of their own customs previous to the contact. Regarding the cartography related to the process of configuration of the microregions corresponding to every accession, is a sample of these exchanges.
\end{abstract}

KeYwords: Territory; Microregion; Time; Space; Symbology. 
La historia es ordenada por la cultura, de diferentes maneras en diferentes sociedades, de acuerdo con esquemas significativos de las cosas. Lo contrario también es cierto: los esquemas culturales son ordenados por la historia, puesto que en mayor o menor grado los significados se revalorizan a medida que van realizándose en la práctica. La síntesis de estos contrarios se desarrolla en la actividad creativa de los sujetos históricos, los individuos en cuestión". M. Sahlins: Islas de historia. ${ }^{1}$

\section{Introducción}

La conformación territorial del área guaranítica, individualizada así por los españoles, ${ }^{2}$ no parece haber tenido una antigüedad mayor a los doscientos años. Según Chase-Sardi, ${ }^{3}$ quien cita a una cantidad importantes de estudios realizados, no existieron migraciones masivas sino que lo que hubo fue una búsqueda de mejores espacios ecológicos y una situación forzada por la metodología agrotécnica del rozado.

En el orden de la máxima expansión guaraní se considera la migración hacia los Andes (Chiriguanos), que posiblemente se realizó hacia los primeros años del siglo XVI, y la migración de los guaraníes que alcanzó el delta del Paraná (Chandules).

Después hubo corrimientos del gentío causados por las sequías o por las plagas y por los focos de enfermedades debidas a la presencia de esteros y pantanos. Estas situaciones incidieron en la división de los grupos más importantes con el objeto de formar asientos más reducidos. ${ }^{4} \mathrm{La}$ posibilidad de delimitar un área guaranítica con cierta homogeneidad se debió a la resistencia de pobladores más antiguos con suficiente capacidad militar para obstaculizar los movimientos de los migrantes. ${ }^{5}$

Con el paso del tiempo, las comunidades guaraníticas y las no guaraníticas mantuvieron relaciones entre sí, con intercambios de mujeres, cuñadazgo y planteamiento de alianzas tácticas para la guerra. Estas alianzas en determinados momentos propiciaron concentraciones de varias macrofamilias étnicamente heterogéneas. ${ }^{6}$

1 Sahlins, 1988, p. 9.

2 Haciendo diferenciaciones en alguna documentación entre guaraníes y tapes.

3 Chase Sardi, 1992, p. 14.

4 González de Santa Cruz, 1994, p. 111. Yapeyú, 15 de noviembre de 1627. “(...) por ser todos campos y no haber montes (=bosques), no hay gente labradora”.

5 Principalmente Charrúas, Yaros y Guaycurúes.

6 Levinton, 2005. 
Por todo ello, para entender lo indígena consideramos como punto de partida de este análisis a la situación de las tierras de los cacicazgos antes del contacto, una cuestión compleja de afrontar por las escasas informaciones al respecto. ${ }^{7}$

En cuanto a la Provincia Jesuítica del Paraguay, nació como respuesta a la necesidad del Gobierno colonial español, al principio con radicación principal en la ciudad de Asunción, de organizar los territorios de habitación de las parcialidades de etnia guaraní con el propósito de implementar mayor cantidad de encomiendas sobre más extensas superficies cultivadas y definir una frontera, en ese momento ya inestable, con los dominios de Portugal. En el contexto de esa política las reducciones de indios actuarían como presidios o guarniciones de fronteras, pero los jesuitas le dieron un carácter diferente, acordando la exclusiva dependencia de los indios con respecto al rey. ${ }^{8}$ En este contexto fue en el que la Compañía de Jesús interpretó que los indios podrían, en forma mediata, integrarse a la sociedad colonial como ciudadanos y, como condición fundamental para ello, deberían ser los dueños de sus tierras.

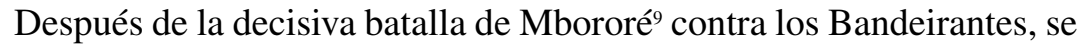
produjo una reorganización espacial que decidió la ubicación definitiva de muchos de los pueblos. Los territorios de los asentamientos tuvieron mayor continuidad entre sí. Desde la margen derecha del río Paraná hasta la margen izquierda del río Uruguay se fueron relocalizando hasta conformar, fundamentalmente con colonias desprendidas de sus pueblos originarios, la Macro-región misionera. Al respecto la documentación del Archivo General de la Nación, de Argentina, referente a los litigios por tierras entre varios pueblos, menciona la situación de algunos cacicazgos y las tierras de los antepasados, en las áreas sujetas a los dictámenes de los jesuitas. En ese sentido, para atender a la cuestión del dominio del territorio en la etapa, es fundamental tener en cuenta el Derecho Natural de la comunidad, una concepción ya discutida e implementada pero puesta en práctica en el área por los sacerdotes jesuitas, y los sucesivos desplazamientos de cada asentamiento. Con estos datos es posible desentrañar también, si lo hubo, el tras-

7 Furlong, 1965, p. 22. El padre Juan de Escandón SJ al procurador general Carlos Gervasoni. Córdoba, 9 de mayo de 1756.; " “(...) cada cacique tenía su diversa porción de tierras cercanas al pueblo, para sus sementeras y las de sus vasallos; las cuales tierras se les daban sus propios dueños (que eran los que estaban allí antes de la fundación de la nueva reducción o pueblo)”.

8 Morales (comp. e int.), 2005, pp. 54 y 56.

9 La batalla se libró en 1641, triunfando sobre los Bandeirantes los indios de las Misiones dirigidos por los jesuitas. 
paso que realizó cada comunidad de su Derecho Natural a otra que posteriormente se radicó en ese lugar durante las idas y vueltas de las relocalizaciones de los pueblos. ${ }^{10}$ Los litigios fueron manejados en algunos momentos por las autoridades coloniales — la más amplia intervención fue la del oidor y gobernador Blázquez de Valverde- ${ }^{11}$ y en otros decidieron los padres provinciales de la Compañía de Jesús. En la mayoría de los casos, esta última alternativa no fue confirmada por las autoridades civiles.

Hacia 1680 una nueva expansión dada por el crecimiento demográfico incitó al planteamiento de litigios que tardaron muchos años en subsanarse. Justamente después de la expulsión de los jesuitas las autoridades coloniales se aprovecharon de la falta de resolución de los conflictos y la ausencia, sospechosa, de mapas y documentos para tomar decisiones sobre los territorios misioneros que no favorecieron a los indios.

En cuanto a la problemática de la organización jesuítico-guaraní del territorio misionero con respecto a la de los pueblos de La Cruz y de Jesús, elegidos por sus particularidades, los procesos de conformación de los territorios de ambos asentamientos se iniciaron en diferentes etapas del proyecto misionero. La idea es realizar un análisis comparativo señalando la influencia jesuítica y la presencia indígena en las cuestiones más relevantes. Si tomamos el año 1609, data de iniciación del proceso de fundación de los pueblos misioneros, como punto de comparación se observa que el asentamiento inicial del pueblo de la Asunción, posteriormente La Cruz, tuvo como fecha de fundación el año de 1630. En el caso del pueblo de Jesús su primer asentamiento estuvo datado en 1685. Esta ubicación cronológica señala que ambos pueblos debieron insertarse en una organización espacial misionera previa, por lo que necesariamente tuvieron que convivir con una cantidad de pueblos originarios dueños del territorio de su asentamiento urbano y, a la vez, con otros pueblos relocalizados, o sea traslada-

10 Furlong, 1965, p. 22. “(...) porque en cada uno de estos pueblos o Reducciones había 15, 20,30, y a veces más parcialidades o caciques con sus vasallos, sucedía inevitablemente a veces, que las tierras de un pueblo estaban interpoladas con las de otro, según el paraje de donde habían venido los de cada pueblo. Y como esta interpolación de tierras, que se destinaban para estancias del ganado que cada pueblo tenía, o esperaba tener, era preciso que causase alguna confusión, los mismos pueblos por consejo y dirección de los Padres Misioneros, hicieron allá su hermanable división de tierras, la que después confirmaron, y aún alguna otra hicieron de nuevo los reales ministros que a aquellas Reducciones pasaron con poder de Su Majestad como pasó el Señor Oidor Don Juan Blázquez Valverde, el año de 1657'.

11 Archivo General de la Nación, Argentina (en adelante AGNA), Sala IX, 22-8-2. Este hecho se produjo en 1657. 
dos desde su primer asentamiento. ${ }^{12}$ La principal consecuencia de estos hechos fue la perfecta o imperfecta ubicación de cada micro-región dentro de la trama espacial de la macro-región misionera, la que se fue definiendo más ajustadamente con el paso del tiempo. ${ }^{13}$

Veremos que el manejo de estos conceptos básicos es fundamental para cumplimentar este artículo. En él, se pretende describir el proceso de la configuración de lo que hemos denominado la micro-región de La Cruz y de Jesús. Al respecto, entendemos que cada micro-región, o sea el territorio correspondiente a cada centro urbano, fue organizado y determinado históricamente por la interacción jesuítico-guaraní. La hipótesis del trabajo es que esta interacción aparece expresada en la cartografía pertinente, especialmente por la expresión en los dibujos de un particular planteamiento de la relación entre espacio y tiempo. ${ }^{14}$ Para todo ello, es esencial la comprensión del lenguaje y del alcance simbólico de las representaciones cartográficas.

\section{La micro-región de La Cruz}

\section{Proceso histórico desde la fundación hasta la ubicación definitiva}

Durante 1629, junto al río Uruguay, se fundó el pueblo de Asunción del Acaraguá. ${ }^{15}$ Una Carta Anua explica en el capítulo dedicado a la Reducción de la Santísima Virgen de Acaraguá que

(...) era por el año de 1635 cuando una grave disentería acabó con quinientas víctimas (...) apenas había terminado esta grave prueba cuando sobrevino a estos habitantes de la reducción de Acaraguá otra mayor: la viruela, por la cual sucumbieron 1300 indios, no habiendo quedado libre de la enfermedad ninguno de los que quedaron con vida. ${ }^{16}$

12 Furlong, 1965, p. 23. Sigue sobre Blázquez de Valverde: “(...) les concedió las que ellas después liberalmente cedieron a los otros tres pueblos que después se fundaron por allí, de Nuestra Señora de Fe, de Santiago y Santa Rosa".

13 AGNA, Sala IX, 7-1-2. Pueblo de San Xavier. Sin fecha (alrededor de 1638), “(..) los capitanes y caciques del pueblo, pidieron a los Padres que antes de empeñarlos en el trabajo lo mirasen bien, no fuese que después de haberles más bien cansado en hacer cosas de propósito, se tratase otra vez de mudanza”.

14 Augé, 1998 (1994), p. 29. Por todo ello, los alcances de este trabajo corresponden en esencia a las incumbencias de la antropología histórica

15 En 1628 se fundó Asunción del Ijhu, que se disolvió por las acciones de los hechiceros y el nombre, por ello, pasó a la siguiente fundación.

16 Cortesao, 1969, p. 185. 
En razón de esta situación, debido a las dos epidemias consecutivas, sólo quedaron 580 habitantes. Por ello se integraron a este pueblo todos los indígenas de la reducción de Jesús María que huyeron de la invasión de los Bandeirantes. Durante esta etapa, parte de la reducción funcionó como un baluarte defensivo estructurado entre el arroyo Acaraguá y el cerro Mbororé. Por ello, la toponimia del asentamiento tuvo ambas designaciones.

La Carta Anua de 1637-1639 dice:

(...) está situada esta reducción al extremo norte entre las reducciones colocadas al margen del río Uruguay, como puesto avanzado contra las invasiones de los lusitanos. Es como el centinela que briosamente espera al enemigo paulista con sus auxiliares indios. ${ }^{17}$

Asimismo, la Carta Anua de 1641-1643 habla especialmente de la Reducción de La Asunción del Mbororé, ${ }^{18}$ porque en esta zona se libró en esos años la decisiva batalla contra los Bandeirantes, pero todavía no informa de ninguna relocalización. Tampoco se recoge en la Carta Anua de 1644, donde se menciona a la Reducción de la Asunción de la Virgen sin especificación del topónimo del asentamiento. ${ }^{19}$ Es en esta etapa cuando, justamente, se produjo la relocalización del pueblo, pues una Carta Anua dice que fue entre 1645 y 1646. ${ }^{20}$ Inmediatamente, parece que el lugar no resultó satisfactorio y se decidió integrar a esta comunidad con los yapeyuanos.

La Carta Anua de 1652 ya sitúa a los cruceños en la periferia de Yapeyú. Pero,

(...) se aprovechan los de Mbororé de ello (...) se les han construído casas y labrado la tierra para que siembren y cosechen... ${ }^{21}$

Evidentemente, este proceder se debió a una cuestión estratégicomilitar de los jesuitas. Una vez disuelta la amenaza de los Bandeirantes y debido a la situación aislada del pueblo de Yapeyú y su escasa población, se decidió reforzar el frente de la frontera con los indios charrúas, ubicando allí una comunidad misionera aguerrida y especialmente entrenada para estas lides.

17 Maeder, 1984, p. 128.

18 Maeder, 1996, p. 100.

19 Maeder, 2000, p. 100.

20 Biblioteca del Colegio del Salvador. Carta Anua de 1652.Traducida por el Padre Leonhardt.

21 Ibidem. 
En el curso de este mismo año de 1652 le fueron adjudicadas a Yapeyú, por el gobernador Blázquez de Valverde, extensas tierras en la Banda Oriental teniendo en cuenta la nueva escala humana derivada de la unión de ambas comunidades.

Pero la unificación entre los dos pueblos se mantuvo sólo hasta 1657.22 Como no se logró entablar una buena relación entre sus cacicazgos, en este año se separaron las comunidades ubicándose Asunción del Mbororé, a partir de ahora La Cruz, en un lugar próximo y a una distancia de 5 leguas.

Un informe especifica que

(...) la doctrina y pueblo de nuestra Señora de la Asunción del Acaraguá y por otro nombre del Bororé tiene más de trescientas familias (...) últimamente se retiró a otro puesto más sano y seguro, está junto a la reducción del Yapeyú cinco leguas. ${ }^{23}$

El nuevo asentamiento, independiente, cumpliría con Yapeyú una función defensiva similar a la asumida en el norte por la relación entre los dos enclaves de La Cruz en Acaraguá-Mbororé. Un indicio de ello sería la construcción de una muralla en todo su perímetro.

Para darle su autonomía al pueblo de La Cruz fue necesario que los yapeyuanos les otorgasen parte de las tierras de su propiedad ubicadas en la banda occidental. Si analizamos la integración de los cacicazgos participantes en la fundación de Yapeyú es evidente que esta comunidad tenía un derecho natural, llamado Derecho antiguo, sobre las tierras de la banda occidental hasta el arroyo Aguapey. ${ }^{24}$ En este caso hubo una donación; así se designaba el procedimiento en los documentos, de una comunidad a la otra $^{25}$ y la cesión, en general, no generó de por sí posteriores litigios.

En cambio, con respecto a las tierras de la banda oriental se planteó sobre determinada zona delimitada por el arroyo Tembetari un litigio que

22 Maeder, 1989, p. 54.

23 Vianna, 1970, p. 337.

24 Aguirre, 1950, p. 349. El autor menciona a todos los cacicazgos que participaron en la fundación del pueblo.

25 AGNA, Sala IX, 6-9-4. Resolución del padre provincial Ignacio de Frías. “(...) Y dado caso que esas tierras en los principios fuesen del Pueblo de los Reyes del Yapeyú, como también todas las demás tierras que poseen sin controversia, y donde está fundado el Pueblo de la Asunción del Mbororé y se les fueron adjudicadas para su fundación y dotación desde antes que se separasen del Pueblo de los Reyes del Yapeyú donde estuvieron, que así lo afirman los indios y los títulos del Padre Provincial Thomás Donvidas lo insinúan bastantemente". Ibidem. Escrito del padre Anselmo de la Matta, “(...) señalado por el Padre Provincial Simón de León para decidir los litigios de tierras”. San Nicolás, 13 de noviembre de 1696. “(...) la liberalidad con que los del Yapeyú han dado sus tierras y ganados mayores y menores sin interés alguno deja como dándose para acomodar a los de la Asunción”, 23 de febrero de 1663 . 
se extendió a lo largo de muchos años. La cuestión, durante la etapa jesuítica, tuvo complicada su resolución especialmente desde 1663 hasta 1700, porque fue cuestionada la donación por diversos sacerdotes. ${ }^{26}$ Según lo señalado en varios documentos, se centró la discusión sobre la problemática de que los indios de Yapeyú hubiesen o no estado totalmente compenetrados del significado de la donación de las tierras.

Uno de los jueces analizó el hecho de que por haberse integrado a Yapeyú parte del gentío de la efímera fundación del pueblo de Candelaria del Ibicuy, los yapeyuanos también tenían derecho natural a extensas tierras en la Banda Oriental. Pero se terminó aseverando que esto regía desde el Ibicuy hacia el sur, pues en uno de los alegatos se consideró que las tierras desde el río Ibicuy hacia el norte no tenían dueño y podían otorgárselas al pueblo de La Cruz. En ese mismo escrito se reforzó la resolución argumentando que este área estaba en la misma línea del centro urbano de La Cruz y por lo tanto las tierras inmediatas le correspondían a este pueblo por configurar el ejido del centro urbano. Con respecto a las que estaban más hacia el norte también les correspondían a los cruceños por haber sido "conquistadas del enemigo". ${ }^{27}$ Para el autor del texto en el que se analiza el origen del diferendo, no era una cuestión de Derecho Natural sino un problema devenido de la pérdida de ganados al efectuarse sin control el pasaje de vacunos de las tierras de un pueblo a las del otro. ${ }^{28}$ Finalmente, la sentencia estableció que había sido válida la donación de los yapeyuanos ${ }^{29}$ y que las tierras les correspondían a los cruceños. En este sentido, una de las resoluciones emitidas, la del provincial Frías, expresa claramente que “(...) los jueces fueron señalados para poner linderos" y, fundamentalmente, que se tendría que haber juzgado por el derecho de la posesión. Para este sacerdote esa era la "(...) primera regla de justicia, que indubijo melior est conditio possidentis".

26 El conflicto perduró después de la expulsión de los jesuitas. En 1769 intervino el teniente de gobernador Zabala. AGNA, Sala IX, 18-5-1. 5 de agosto de 1769. “(...) habrá como siete leguas por común y realengo para que estos dos pueblos puedan cortar las maderas y cañas que hay en él”.

27 AGNA, Colección Biblioteca Nacional, Legajo 361. Firmado por el padre Joseph Saravia durante el provincialato del padre Ignacio Frías (1698-1702). "Prueba Real de que el convenio intentado por su Ra. del Padre Provincial es más nocivo que la mejor sentencia".

28 Ibidem. "(...) ha vuelto la materia de la disensión que es la mezcla de ganados".

29 AGNA, Sala IX, Legajo 6-9-4. Resolución del padre provincial Ignacio de Frías del 28 de noviembre de 1699. Biblioteca Nacional de Río de Janeiro (en adelante BNRJ), I-29-3-46. Copia de la posesión dada por el padre Bernardo de la Vega de la Compañía al pueblo de La Cruz de las tierras de que fueron desposeídos por el padre provincial Simón de León. 27 de enero de 1700. 
A pesar de la resolución, este área limítrofe volvería a ser objeto de litigio después de la expulsión de la Compañía de Jesús. En febrero de 1769, el teniente de gobernador del Departamento de Yapeyú afirmó en una carta que

(...) este de Yapeyú sólo tiene un título dado por un Padre de la Compañía y no habla de aquel paraje sino de la otra banda del Ibicuy y el Ibirapuita guazu. ${ }^{30}$

El asunto había sido resucitado por el administrador Gregorio de Soto. El Cabildo yapeyuano aseguró que

(...) los montes [del área litigada] son los únicos que tenemos nos vemos precisados a comprar maderas y cañas para nuestros edificios. ${ }^{31}$

A su vez, el administrador justificó esta acción diciendo que

(...) es cierto que quitando dicho terreno a este Pueblo en todo el que le resta no tiene de donde sacar un palo para la reedificación de sus habitaciones como ni tampoco para la Santa Iglesia que por instantes amenaza ruina. ${ }^{32}$

Zabala impuso su autoridad y solucionó rápidamente el conflicto. En su informe reconoce que el Pueblo de La Cruz tenía la “(...) posesión de más de cuarenta años" y que los yapeyuanos sólo contaban con un título, dado por un padre de la Compañía, que no estaba referido a aquel paraje. ${ }^{33}$ Ante tales circunstancias, por razones políticas, ${ }^{34}$ decidió en su veredicto establecer como "común y realengo" al sector "desde el Tembetarí hasta enfrente del Ibipitá [unas 7 leguas] (...) para que estos dos Pueblos puedan cortar las maderas y cañas". ${ }^{35}$ Este funcionario aprovechó las circunstancias para mostrar las bondades del nuevo sistema de gobierno. ${ }^{36}$

La misma tónica se advierte que fue implementada en el litigio entre el pueblo de La Cruz y el de San José por el área montuosa denominada Mangaratí. ${ }^{37}$ Así se lo explica Zabala a Bucarelli:

30 AGNA, Sala IX, 18-5-1. Yapeyú, 7 de febrero de 1769. Francisco Bruno de Zabala al gobernador Bucarelli y Ursúa. Afirma que "(...) en el mismo papel hay un mapa".

31 Ibidem. Yapeyú, 12 de febrero de 1769. El Cabildo al gobernador Bucarelli y Ursúa.

32 Ibidem. Yapeyú, 16 de junio de 1769. Firmante Gregorio de Soto.

33 Ibidem. Yapeyú, 7 de febrero de 1769. Zabala a Bucarelli y Ursúa.

34 Ibidem. San Borja, 26 de noviembre de 1769.

35 Ibidem. San Borja, 16 de noviembre de 1769. Zabala a Bucarelli.

36 Ibidem. San Borja, 26 de noviembre 1769. Zabala a don Francisco de Sanginés. “(...) todos los pueblos tienen sus pleitos por tierras, los jesuitas los dejaron enredados".

37 Ibidem. 12 de mayo de 1769. Juan Gregorio Fernández a Zabala. El lugar del Mangaratí estaba a 8 leguas rumbo al nornoroeste junto a la parte occidental del río Aguapey. 
(...) lo definí dividiendo el expresado monte entre estos dos pueblos y han demarcado y amojonado su división. ${ }^{38}$

Este acuerdo seguramente figuraba en alguno de los mapas que formaban parte del inventario realizado en el Archivo del Cabildo de San José algunos años después. El documento menciona todos los instrumentos legales con que contaban sus autoridades indígenas: ${ }^{39}$

-Dos mapas de las tierras de este pueblo y el de La Cruz

-Un mapa de los montes, ríos y tierras linderas del pueblo de San José con el de los Santos Mártires

-Otro mapa de las tierras del Pueblo de La Cruz

-Un mapita de los términos de las estancias de este Pueblo y de otro en el Aguapey.

Hacia 1784 existía en el Archivo de Candelaria "un mapa en Pergamino de las tierras de Yapeyú y La Cruz" que, con certeza, es uno de los que vamos a analizar. ${ }^{40}$

\section{Lectura del mapa 1}

Hubo varios elementos que se utilizaron para definir los límites de las micro-regiones. Fue común la instauración de tres cruces, el uso de zanjas o fosos y el apoyo en accidentes geográficos como ríos o cerros. ${ }^{41}$ La metodología establecida, por diversas razones, sufrió alteraciones en el transcurso del tiempo. Pero la simbología siempre tuvo un papel destacado en la discusión de las propiedades y ajenidades planteadas en cada litigio.

Un ejemplo paradigmático de lo que aparece en la cartografía es el del sistema de la "libreta de apuntes", pensamos que puesto únicamente en práctica por el sistema cultural misionero.

El primer mapa a analizar se encuentra en un inventario correspondiente al pueblo de La Cruz. Se trata de un

38 Ibidem. San Nicolás, 10 de abril de 1770. Ver también las cartas anteriores de Zabala a Bucarelli del 11 de mayo de 1769 y de Juan Gregorio Fernández a Zabala del 12 de mayo de 1769.

39 AGNA, División Colonia, Sección Gobierno, Cargo y Data. Sala IX, Legajo 17-5-4. Año 1782. Pueblo: San José.

40 AGNA, Sala IX, 22-2-7. Memoria de los títulos, pertenencias de tierras, Pleitos y otros papeles correspondientes a estos Pueblos que quedan en el archivo de esta Capital.

41 Azara, 1904, p. 78. “(...) un foso o zanja que divide las tierras de ambos pueblos". 
(...) papel [que] de nota las dos vaquerías que hicieron los Naturales de este Pueblo en los años de mil setecientos cuatro y mil setecientos siete en los campos y rincón del Caraguataí y Tacuarembó. ${ }^{42}$

Como hubo una discusión sobre ese ganado con otros pueblos, este "papel" [mapa] fue guardado y conservado en el Cabildo de La Cruz. Según el gobernador militar Francisco Bruno de Zabala fue “(...) heredado de sus antepasados por tradición e informe de las tierras que poseen". Y agregó "(...) que se conserve en el Archivo de Cabildo y se saque en copias de él autenticadas". ${ }^{43}$

En el mismo legajo se encuentra otro mapa más importante. Sabemos —está escrito en la parte posterior-que el 10 de septiembre de 1784 los cruceños lo presentaron a una requisitoria del Gobierno de Buenos Aires. Evidentemente, en su origen no era un mapa hecho para tal propósito, sino que venía de la época jesuítica.

En el legajo donde está el mapa hay un Inventario del pueblo de La Cruz desarrollado en 1784. En dicho documento aparece, como antecedente y documento base, un escrito del padre Dombidas correspondiente a 1688. Allí se determina una línea limítrofe progresiva basada en letras. ${ }^{4}$ Estas letras están en el mapa que estudiamos. Esto quiere decir que el mapa pudo haber servido a los cruceños, por lo menos, desde 1688 hasta 1784 o, en todo caso, existió una serie de mapas sucesivos en los cuales se fueron agregando diferentes inscripciones.

Coincidimos con el historiador Julio César González cuando dice que se confeccionó en 1784 “(...) sobre un original, sin duda alguna, de origen jesuita". ${ }^{45}$ González justifica esta afirmación por el nivel de conocimiento

42 AGNA, Sala IX, 22-8-2. 14 de septiembre de 1784. Firman las autoridades del Cabildo. Figura el capitán o cacique que realizó la vaquería y el número de reses que formaron parte de la misma en un dibujo de la zona donde se realizó.

43 Ibidem. El texto del gobernador militar es del 4 de mayo de 1769. Toda la documentación fue autenticada por las autoridades del Cabildo el 10 de septiembre de 1784 .

44 Ibidem. Inventario de los Bienes Comunes del Pueblo de Indios Guaraníes nombrado La Cruz. Año de 1784. “(...) para que en ningún tiempo nadie les moleste ni inquiete su pacífica posesión digo y declaro por términos de la estancia de la otra banda del Uruguay donde tienen sus vacas y se llama el Itaquí comenzando el término de dicha estancia desde la otra banda del Uruguay corre hacia el oriente y llega hasta el A Ibiptia Mirí (...) por un cerrillo costado desde el B "(sigue).

45 González, 1940, pp. 5, 12 y 13. “(...) En el ángulo inferior derecho de este mapa, cuyas dimensiones son de $77 \times 56 \mathrm{~cm}$, se inicia una leyenda que luego continúa a la vuelta, que dice así: "Está conforme al original que para en el Archivo de este Pueblo al que en todo tiempo nos remitimos y para que conste haya la debida fe lo firmamos en el Pueblo de la Cruz a catorce de septiembre de mil setecientos ochenta y cuatro años. Josép Guiyu Corregidor" (...). Nada nos dice de la antigüedad del original pero observando la reproducción de esta copia de 1784, se advierte que figuran marcadas capillas, ríos y arroyos tributarios que denotan conocimiento amplio del terreno". 
regional, de detalles inherentes a la geografía física, expuesto en el mapa. Nuestra idea es que, para cumplir con el trámite, si se corrigió algo en este último año sólo puede haber sido el trazado del límite entre los pueblos de La Cruz y Yapeyú, correspondientes a la Banda Oriental del río Uruguay, un litigio con la última acción conocida desarrollada en 1769-1770.

Está claro que el propósito fundamental del mapa siempre fue mostrar los límites del territorio de los pueblos que figuraban allí, o sea de la respectiva micro-región. ${ }^{46}$ González sugiere que el mapa pudo haberse traspapelado al haberlo encontrado entre papeles correspondientes al pueblo de Mártires. Pero, encontramos un documento que señala el desarrollo de un litigio en el que tuvo que ver este último pueblo y en él pudo haberse utilizado este dibujo. ${ }^{47}$ Evidentemente, fue un instrumento funcional para varios conflictos. Como explicamos ut supra, esto era algo acostumbrado y los instrumentos debían estar a la mano. ${ }^{48}$ Todos los documentos, especialmente los mapas, normalmente se copiaban para diferentes requerimientos $\mathrm{y}$ trámites.

González duda del grado de la intervención de los indios en su preparación. Coincidimos con este autor en que el dibujo básico fue realizado por un jesuita. Hay demasiados comprobantes de la autoría de diversos mapas por parte de diferentes sacerdotes, especialistas o no en el tema. ${ }^{49}$ Estos ejecutores emplearon instrumentos que exigían estudios de topografía, geodesia y matemáticas. Pero, estamos convencidos de que los indios utilizaron la trama básica para diversos trámites, la copiaron varias veces y le escribieron encima.

Este mapa también funcionó como "libreta de apuntes". Obsérvese a un costado del río Miriñay una anotación con la fecha 1753 en guaraní. Asimismo hay varias frases, también en guaraní, con la fecha de 1716, y

46 Ver el trabajo de González donde se describe el legajo que incluye la petición de las autoridades de Buenos Aires y la respuesta de varios pueblos.

47 AGNA, Sala IX, 18-5-1. San Borja, 26 de noviembre de 1769. “(...) lo practiqué estos días aprobando una composición que hicieron los del Pueblo de Santo Thomé por solicitud mía con el Pueblo de los Mártires".

48 AGNA, Sala IX, 22-9-2. Inventario del pueblo de La Cruz correspondiente al año 1789. “(...) Sala Capitular (...) Papelera con dos divisiones y dentro el Real Estandarte, un Libro de Acuerdos, Papeles de elecciones, Confirmaciones, Títulos y algunos Mapas”.

49 Furlong, 1945, pp. 87 a 100. De este mismo autor, 1955, p. 19. Él menciona a varios sacerdotes jesuitas del siglo XVIII como autores de mapas. Entre ellos los padres Chomé (1696-1768), Sánchez Labrador (1717-1798), Xavier Limp (1696-1769), Marimón (1710-1775), Henis (1714-1769), Falkner (1707-1784) y, por supuesto, el padre Quiroga (1707-1784), único de ellos que figuraba como geógrafo. 
cerca del límite oriental de la micro-región de La Cruz inmediata a la línea fronteriza se distingue la clásica cruz. Pero, fundamentalmente, es impresionante la riqueza de los datos que aporta. Están marcados los límites de los territorios de varios pueblos y las estancias de otros, como una de Mártires y otra de San Joseph, discontinuas con los territorios de ambos asentamientos. En estos casos, había una servidumbre de paso perfectamente establecida.

Además el mapa presenta una amplia simbología, como las pequeñas manchas asemejando pisadas, atribuibles especialmente a la denotación de picadas para el manejo del ganado. Por eso también figuraban los pasos de los ríos y los abrevaderos.

Asimismo, llama la atención la fina descripción de las Iglesias, como referencia particular, quizás para destacar el carácter del pueblo. En estos pequeños edificios se denotan sus transeptos y cúpulas, diferenciándose netamente los que carecían de estas complejas resoluciones arquitectónicas, seguramente más antiguos.

\section{La micro-región del pueblo de Jesús}

\section{Proceso histórico desde la fundación hasta la formación del último asentamiento (sólo parcialmente utilizado)}

La documentación histórica sobre el proceso de formación del pueblo de Jesús reseña el área como habitada por indios guaraníes llamados monteses. Estos fueron denominados de tal manera por haberse mantenido apartados de los españoles, habitando en áreas de vegetación tupida.

La zona era especialmente atractiva para los españoles por la existencia de importantes yerbales. Los franciscanos de las reducciones de Yutí y Caazapá, los más próximos a las aldeas de los indios monteses, no pudieron encargarse de ellos por la falta de sacerdotes idóneos. ${ }^{50} \mathrm{Al}$ ser encarados por las autoridades españolas civiles y religiosas, los jesuitas aceptaron

50 Necker, 1990, p. 120. “(...) Luis Bolaños, ayudado por algunos compañeros, fue el obrero principal. En 1606, él se llegó hasta la provincia del Iviturusú y comenzó a agrupar a los linajes guaraníes en un pueblo al cual se daría el nombre de Caazapá”. BNRJ, I-29-2-69. Exhortatorio para la conversión de los gentiles que hablaron con el cura de Caazapá. El gobernador Felipe Reje Corvalán, ante la negativa de los franciscanos, se comunicó en 1678 con el padre provincial Nicolás del Techo. AGNA, Colección Biblioteca Nacional, Legajo 181. Real cédula del 20 de abril de 1681 firmada por mandato del rey por Francisco Fernández de Madrigal. 
la organización de un nuevo asentamiento misionero. ${ }^{51}$ El pueblo de Jesús fue fundado el $1^{\circ}$ de enero de 1685 a la vera del Monday.

$\mathrm{Al}$ año siguiente tuvo su primer traslado a un lugar bastante lejano, siendo la causa de ese cambio la amenaza de ataques de indios tupíes. El sitio fue denominado Jesús del Ibarotí. A pesar de todo el esfuerzo invertido en 1690, los jesuitas se volvieron a trasladar al área comprendida entre el arroyo Mandiisoby y el Capiibary. ${ }^{52}$ La carta que explica el proceso de traslado describe la solidaridad de los indios de otros pueblos para resolver la producción agrícola necesaria para el alimento del gentío y las construcciones mínimas indispensables. Un aspecto importante de esa solidaridad fue la cesión de tierras efectuada por el pueblo de Corpus, originario de ese lugar, en tres momentos diferentes. ${ }^{53}$

El nuevo pueblo quedó dispuesto en 1691 y tres años más tarde -1694- los jesuitas recibieron otra cesión de tierras realizada por los pueblos de Corpus e Itapua. ${ }^{54}$ A su vez, en 1712, estos religiosos cedieron tierras para la configuración de la micro-región del pueblo de Trinidad. ${ }^{55} \mathrm{El}$ asentamiento de la reducción de Jesús estuvo en ese lugar hasta 1714.

51 Ibidem. "Aceptación por parte de la Compañía de Jesús de la conversión de los indios infieles monteses" ante el obispo del Paraguay fray Faustino de Casas. Ver el Auto del 19 de julio de 1684. AGNA, Sala IX, 10-7-4. Documentos del Archivo del Pueblo de Jesús presentados como Testimonio en el año 1784 para el litigio con el Pueblo de Yutí. La autoridad civil, el gobernador del Paraguay Antonio de Vera Múxica, firmó el Auto de 1685.

52 AGNA, Sala IX, 6-9-4. Carta al provincial firmada por el padre Jerónimo Delfín. 20 de septiembre de 1690. “(...) el paraje es el mejor que hay en las doctrinas, entre dos arroyos y tan capaz que una Sevilla se podía fundar, muy alegre y coronado de montes, está a 4 leguas del Paraná, no tiene hormigas, diez lomas están todas a la vista unas de otras cualquiera de ellas la mejor para el Pueblo, al Padre Superior le agradó más esta".

AGNA, Sala IX, 22-2-7. "Memoria de los Títulos, pertenencias de tierras, Pleitos y otros papeles correspondientes a estos Pueblos que quedan en el archivo de esta Capital (Archivo de Candelaria). Buenos Aires, 28 de agosto de 1784. "Licencia para mudar el Pueblo de Jesús del Ibarotí adonde está ahora por el Gobernador del Paraguay Don Francisco de Momforte en diecisiete días del mes de noviembre de mil seiscientos y noventa años".

53 AGNA, Sala IX, 10-7-4. “(...) en veintidós del mes de mayo del año de mil seiscientos y noventa el Corregidor del Pueblo de Corpus Antonio Abaró, el Teniente Ignacio Chips y todo el Cabildo, Alcaldes y Regidores con los Caciques de dicho Pueblo a petición del Padre Superior Salvador de Rojas damos espontáneamente y graciosamente a los del Pueblo del Jesús para su nueva fundación las tierras que de la otra parte del Paraná tenemos y gozamos como señores legítimos suyos por haber sido de nuestros padres y Abuelos que son las tierras, campos y montes que están de la otra banda del Arroyo que llaman Capiibary aguas abajo hasta el Paraná y aguas arriba hasta el Paraje llamado Mbaéporomocó

54 AGNA, Sala IX, 6-10-5. Jesús, 4 de noviembre de 1762. “(...) señalar todas las tierras que el año de 1694 el Corpus e Itapua dieron al Jesús".

55 Ibidem, Jesús, 24 de noviembre de 1762. “(...) Pero sobre todo en lo que principalmente estriba y alega este Pueblo como razón única y principal es la Cruz de división de tierras de estos dos Pueblos Trinidad y Jesús, la que levantó el Padre Sebastián Ramírez SJ en concurrencia y a vista de los dos Cabildos trinitario y jesuato, el año de 12 cuando el Jesús dio sus tierras a la Trinidad”. 
En 1715 se dio inicio a otro centro urbano ubicado al occidente del arroyo Capiibary. Al año siguiente se planteó un litigio con el Pueblo de Yutí por la Estancia del Ñuguazú, que resultó en la celebración de un convenio..$^{56}$

Durante esta etapa los jesuitas, por alguna razón que desconocemos, cuando era cura de la Reducción el padre Bernardo Nussdorffer, plantearon la necesidad de un nuevo traslado. Un Memorial de 1722 expresa:

(...) La mudanza del Pueblo se suspenderá por el desconsuelo que tienen los Indios en hacerla; pero no por esto se dejarán de hacer casas para los Indios como hasta ahora se ha hecho. ${ }^{57}$

Pero dos años más tarde otro memorial sugiere el corrimiento del asentamiento a un lugar próximo. El documento dice:

(...) Antes de emprender la obra de la plaza y lo demás en el sitio señalado, se registrará la loma por las personas que yo señalare para que vean si se ofrece alguna dificultad, la cual se me propondrá si la hay. ${ }^{58}$

La permanencia en esa ubicación duró hasta 1748. Luego, nuevamente se trasladaron a otro enclave que terminó siendo, debido a la expulsión de la Compañía de Jesús, el asentamiento definitivo.

Durante 1755 el pueblo de Jesús le compró tierras al del Yutí, transacción que fue establecida por un título legal. Al año siguiente se realizó otra transacción similar confirmada por escribano público. ${ }^{59}$

Unos años después se intentó disponer de otro sitio para el pueblo, infructuosamente, en una altura muy próxima. En este lugar, llamado Jesús del Tavarangüe, se construyó la iglesia, el colegio y varias viviendas. La mayor parte de las construcciones no se terminaron. Cada sector de edificios alcanzó un grado de avance diferente.

En febrero de 1760 se inició un pleito entre Jesús y Trinidad por la posesión de la Calera de Itaendí. Según el cura de Jesús, padre Juan Antonio de Rivera, el motivo era la construcción de la nueva iglesia de

56 AGNA, Sala IX, 22-2-7. Yutí, 16 de agosto de 1716. AGNA, Sala IX, 6-10-6. Jesús, 6 de abril de 1764. "(...) unas tierras que tiene pobladas este Pueblo con convenio, cesión y beneplácito del Yutí desde el año de 16 [se refiere el autor a 1716]".

57 AGNA, Sala IX, 6-9-5. Jesús, 10 de marzo de 1722.

58 AGNA. Sala IX, 6-9-6. Jesús, 24 de marzo de 1724.

59 AGNA, Sala IX, 22-2-7. 
Trinidad ${ }^{60}$ Lo cierto es que después de que los sacerdotes intervinientes como jueces decidieran darle la razón al pueblo de Jesús, el cura de Trinidad volvió a plantear el pleito aduciendo que tenía nuevos elementos de prueba. Una carta escrita por el padre Rivera revela que se hizo una investigación histórica para sustentar los dichos. ${ }^{61}$ Este sacerdote afirma que

(...) advierto a VRa como el Padre Quintana (uno de los jueces) después que vio y supo como el Padre Astudillo no era Cura el año que dicen los Itapuanos haber dado estas tierras, me dijo en su Pueblo que lo que antes había dicho a favor de la Trinidad, ya no lo decía.

Pero lo más interesante para este trabajo, es que aparecen en el mapa de Jesús varios de los datos que refuerzan estos comentarios.

En 1763 se volvió a recrudecer el conflicto con el pueblo franciscano de Yutí por la posesión de los yerbales. En la mayoría de los casos de pueblos que se dedicaban a la recolección de este producto nunca el Gobierno colonial les había otorgado la propiedad de yerbales naturales. A lo más, se les concedió una tenencia provisional vinculada con la antigüedad del uso. Pero este caso era diferente porque los yerbales estaban ubicados en áreas que habían sido habitadas por los jesuitas.

$\mathrm{Al}$ respecto, expresó el padre Rivera:

(...) Lo que yo suplico con todas veras a VRa es el que se haga lo posible para que este pueblo no pierda los famosos Yerbales de sus tierras originarias". ${ }^{62}$

Por los intereses en juego, la marcha del asunto en los tribunales de Asunción, en donde había intereses contrarios a los jesuitas, se vio comprometida. ${ }^{63}$

En este mismo año salió la sentencia definitiva del pleito entre los pueblos de Jesús y Trinidad. Por ella se confirmó el derecho de los habitan-

60 AGNA, Sala IX, 6-10-5. Jesús, 15 de octubre de 1761. “(...) las tierras que este Pueblo de Jesús está poseyendo desde el año de 1690 (...) hace al Jesús en pago de haberle dado este sus tierras cuando el año de 1711 vino aquí la Trinidad".

61 Ibidem, Jesús, 17 de octubre de 1762. Carta dirigida al padre visitador Nicolás Contucci. Contucci.

62 AGNA, Sala IX, 6-10-6. Jesús, $1^{\circ}$ de agosto de 1763. Carta al padre visitador Nicolás

63 Ibidem, Jesús, 14 de enero de 1765. “(...) le doy a VRa las gracias por las diligencias sobre los Yerbales de este Pueblo; si bien me temo y no sin fundamentos el que a buenas no conseguiremos nada”. 
tes de Jesús a la Calera de Itaendí. ${ }^{64}$ Todo el conflicto terminaría con la colocación de los mojones para delimitar las tierras. ${ }^{65}$

$\mathrm{Al}$ año siguiente, se recrudeció de nuevo el conflicto por los yerbales. Según el padre Rivera, la gente del Yutí estaba patrocinada por españoles de Villa Rica, comercialmente interesados en el producto. ${ }^{66}$

El cura de Jesús realizó un erudito y sustentado escrito jurídico en 1765 sobre los derechos de ese pueblo. El padre Rivera, defendiendo enérgicamente a su gente, criticaría un año más tarde la falta de la debida atención del caso por parte de las autoridades de la Compañía de Jesús. ${ }^{67}$

Después de la expulsión continuó el litigio durante largo tiempo. ${ }^{68}$ Una carta del gobernador militar de Misiones, Francisco Zabala, se ocupó del tema en $1777^{69}$ y otra carta fue escrita por el cura del Yutí en 1780, ${ }^{70}$ acusando a los jesuitas de haber cambiado la toponimia. En 1784 todavía continuaba el conflicto.

\section{Lectura de mapas 2-5}

En la primera parte del mapa llama la atención como se señala la ubicación de la primera fundación del pueblo de Jesús. Allí los jesuatos, como se designaba a los habitantes de Jesús, estuvieron sólo un año.

64 Ibidem, Córdoba, 30 de noviembre de 1763. Ibidem, Jesús, 4 de octubre de 1764. En esta carta, dirigida tmbién al padre visitador Contucci, el cura de Jesús aclara los alcances de la sentencia a su favor. Dice que los Jesuatos (habitantes del pueblo de Jesús), por complacer al Padre Contucci, cedieron al pueblo de Trinidad "las tierras que vienen desde el desemboque del Capiibari Guazu en el Paraná hasta dicho Pueblo de la Trinidad. Le da también los campos llamados el Yataiti, que el año de 94 Itapua había dado al Jesús. Y a estas tierras añade una rinconada bien capaz, la que junta con las antecedentes son superabundantes para los ganados que la Trinidad puede mantener en su Pueblo. Y esto sólo por hacer bien y por mediar el empeño de VRa".

65 Ibidem. El padre Valdivieso, cura de Trinidad, al visitador Contucci. Trinidad, 12 de diciembre de 1765. “(...) En viniendo el Padre Superior Esteban Fina me dice su Ra que hará se levanten los mojones o linderos según dice y nombra dicha sentencia dada en Córdoba, sin atender más ni a títulos antiguos ni a otro papel alguno".

66 Ibidem, Jesús, 6 de abril de 1764. “(...) los indios del Yutí patrocinados de los villenos (como interesados en ello) no sólo pretenden para sí los Yerbales de este Pueblo".

67 AGNA, Sala IX, 6-10-7. El padre Rivera al visitador Contucci. Jesús, 11 de junio de 1766.

68 BNRJ, I-29-5-62. 29 de julio de 1776. Carta al señor capitán general. “(...) echaron luego a nuestros hijos de nuestro yerbal que estaban trabajando en beneficio de la yerba; luego el Corregidor del Yutí introdujo a sus hijos, a los del Pueblo de Caazapá y españoles”.

69 AGNA. Sala IX, 17-6-3. Carta del 23 de abril de 1777.

70 AGNA. Sala IX, 17-7-2. El cura del Yutí al gobernador y capitán general, 31 de mayo de 1780 . 
Evidentemente, no fue iniciado el mapa en esa época. ${ }^{71}$ Hacia la izquierda de esta parte del mapa aparece un dibujo correspondiente al segundo asentamiento de 1686. Figura allí la referencia "Pueblo antiguo de Jesús del Ibarotî", otro indicador de la época de la hechura por la designación "antiguo". Alrededor del mismo, el dibujo de la extensión precisa de las primigenias tierras de las chacras pertenecientes a cada cacicazgo de Jesús da pie a suponer que este mapa se basó en uno más antiguo. Es interesante ver que varias veces más aparece el rótulo "donde habitaron los del Jesús", siempre con la letra chica, junto a los lugares referidos como yerbales del Jesús. Esto lo refrenda la minuciosa enumeración de los años de recolección de yerba realizada por la gente de Itapua.

Más abajo, aparecen los nombres de los padres Dáttilo y Arce. Al respecto, Furlong destaca en su Cartografía ${ }^{72}$ que:

(...) el singularísimo mérito de esta pieza reside en ser obra de un indio, como se comprueba por la caligrafía típica de los indios de las Reducciones, por las múltiples frases totalmente en idioma guaraní y por usar la expresión Pay Joseph Arce, Pay Hypólito Dactilo, al consignar la localidad donde fueron muertos estos misioneros.

Enseguida, el mismo autor menciona que por el nivel de información del mapa es posible inferir que se compuso a principios del siglo XVIII. Estas afirmaciones ahora son materia de discusión porque pudimos encontrar otras dos partes del mismo mapa. ${ }^{73}$ La mayor dificultad fue entender las diferentes letras escritas sobre el documento y la traducción de esas inscripciones.

Es fundamental saber que los padres Arce y Dáttilo estuvieron en el pueblo de Jesús casi inmediatamente después del momento de su fundación. Fueron dejados a cargo del mismo por el padre superior Francisco de Rojas y por el cura Jerónimo Delfín hacia 1686, en el asentamiento del Ibarotí. El padre Hipólito Dáttilo murió el 6 de septiembre de 1708 en Córdoba. Pocos años más tarde, en 1715, falleció el padre José Francisco Arce por acción de indios Payaguás en la zona de Pataguá (cercana al río Paraguay en camino desde los Chiquitos).

71 El documento "Razones sobre el derecho..." cita la obra del padre Francisco Xarque que fue editada en 1687.

72 Furlong, 1946, pp. 42 y 43. En el catálogo figura con el número 16 y su encabezamiento dice: "Mapa compuesto por un indio guaraní y en el que se consignan las estancias de algunas reducciones". Masy SJ.

73 Esto pudo ser posible por una gestión llevada a cabo por el padre Rafael Carbonell de 
En el mapa aparece el nombre de ambos y una cruz en lugar cercano a donde estaba el asentamiento del pueblo de Jesús en el momento del fallecimiento del último de los nombrados. O sea, que se trató de un homenaje in memoriam de su buen proceder como curas de la reducción. Un aporte a la identidad y a la memoria histórica de los jesuatos.

Por eso, podemos decir que, en esencia, la existencia de la letra más pequeña corresponde al uso del plano como una "libreta de apuntes" y la letra más grande y en color rojo pertenecería a la toponimia básica.

Esta rememoración tiene que ver con los litigios que sostuvo el pueblo de Jesús con el del Yutí por los yerbales. Dice en un documento referente a este proceso que las "tierras las reconoce por suyas por haber sido de sus progenitores". Esto significaría que el autor de esa letra recogió todo el conocimiento histórico de la memoria de los religiosos de la Compañía. Dice el documento de 1765, refiriéndose a las tierras y yerbales, que el pueblo de Jesús:

(...) las ha poseído y defendido desde su primera fundación que se hizo más ha de 80 años, son todas las del Monday, Ibarotí, Piray, Uruguay (un río que entra al Paraná por el norte), Yaguy y Guirapoy. Y la razón es porque en todos estos parajes vivieron como en tierra propia. ${ }^{74}$

Así, podemos afirmar que la hechura del mapa corresponde indudablemente a $1765 .{ }^{75}$ Pero esto no quita que se haya basado en piezas cartográficas más antiguas.

\section{Conclusiones}

Es posible afirmar que en los mapas, independientemente de los datos políticos, físicos y de la toponimia, se anotaron diversos acontecimientos de importancia en la historia del pueblo. Estas informaciones, seguramente vitales para cada comunidad, las relacionamos con el concepto filosófico de tiempo que Meliá atribuye a los guaraníes. Éste afirma que:

74 AGNA, Sala IX, 6-10-6. "Razones sobre el derecho...".

75 Ibidem, "Razones sobre el Derecho que el Pueblo del Jesús, que está a cargo de los Doctrineros de la Compañía de Jesús, tiene a las tierras y yerbales que posee y reconoce por suyos, en contraposición del que pretenden tener los Pueblos de San Francisco del Yutí y San Joseph de Caazapáque que están a cargo de la Religión Seráfica”. 
(...) con los guaraníes se puede construir con relativa facilidad un modelo tridimensional que ensambla en el mismo conjunto prehistoria, historia y modernidad. ${ }^{76}$

Algo similar plantean Viveiros de Castro y Carneiro da Cunha sobre la cultura guaraní cuando analizan la cuestión del concepto de tiempo para los indígenas. ${ }^{77}$ Pero es Chamorro quien más desarrolla esta categorización cuando se refiere al "permanecer delante del objeto" o al "tiempo reducido". ${ }^{78}$

Así como en los cantos, analizados por esta última investigadora, las aposiciones eran figuras que ordenaban la secuencia de ideas y establecían conexiones “(...) entre episodios (diversas fiestas), tiempos (pasado y presente) y personajes (rezadores actuales del plano histórico y héroes culturales del plano mítico) confundiendo los tiempos, los planos de realidad y la identidad de los personajes"; de una manera similar se presentaron a nuestra comprensión los escritos esparcidos por los mapas.

Por eso, cuando Chamorro, en otro trabajo, habla de los ancianos que cuentan "cosas memorables" dice que:

(...) la persona que cuenta repite para que lo memorable se quede, para renovar cosas pasadas.

Repetir en un mapa, retomando una frase de esta autora, también es "guardar el pasado en un papel", pero no sólo como cuentos de viejos sino como una actitud de compromiso con su propia tierra. ${ }^{79}$

Esto revela que hubo un intenso proceso de conformación de las diferentes micro-regiones y que los mapas, de alguna manera, nos hablan de ello. ${ }^{80}$ Por esta razón, se puede plantear que la cartografía misionera contiene una historia del espacio producida por una concepción jesuíticoguaraní. ${ }^{81}$

76 Meliá, 1996, p. 184.

77 Carneiro da Cunha y Viveiros de Castro, 1986.

78 Chamorro, 2004, p. 255.

79 Chamorro, 2007, p. 17. “(...) tuja y guaivi no se refieren únicamente a personas de avanzada edad, sino también a quienes se orientan por el saber de antaño, de viejos y viejas”.

80 AGNA, Sala IX, 18-5-1. Yapeyú, 7 de febrero de 1769. El teniente de gobernador Zabala, en lo referente al litigio de Yapeyú y La Cruz, dice en una carta que tenía ya citado al Cabildo de este Pueblo [Yapeyú] “(...) para oírles y ver sus Instrumentos y Mapas”.

81 Evidentemente hubo en las reducciones una discusión entre los sacerdotes y los indios sobre el concepto filosófico del tiempo. El padre José de Insaurralde fue autor de un libro denominado "Ara porú aguiyey" o "Del buen uso del tiempo". Furlong, 1965, p. 43. 
Eran tan complejas estas disputas, especialmente por la necesidad de componer una revisión histórica, que en una carta al geógrafo Joseph Quiroga ${ }^{82}$ el padre visitador Nicolás Contucci le recomienda encarecidamente la confección de mapas más exactos:

(...) los mapas antiguos están defectuosos, se hace preciso que usted trabaje uno nuevo, ayudándose de las recientes observaciones para corregir los defectos antiguos. Y porque VRa no ha corrido toda la Provincia del Paraguay, ni Chiquitos podrá gobernarse por los antiguos mapas". ${ }^{83}$

Después de la expulsión de la Compañía de Jesús, se volvió a procurar darle un carácter definitivo a la configuración de las micro-regiones.

Dice el gobernador Zabala en 1787:

(...) Por cuanto en oficio de 16 de noviembre antecedente (...) me pide una relación circunstanciada de la Capital de este Gobierno y de sus Partidos (...) estos 30 Pueblos harán cada uno de por sí sacar con la prontitud y prolijidad de vida copia de los Mapas que existen en los Archivos así del terreno de las inmediaciones del Pueblo como de sus estancias procurando se distingan en ellos los Ríos, Arroyos, Montes y Cerros (...) las leguas que comprende el distrito de él, sus términos y divisiones con los Pueblos inmediatos del contorno. ${ }^{84}$

Recibido el 30 de junio de 2008 Aceptado el 7 de octubre de 2010

\section{Bibliografía}

Juan Francisco de Aguirre: "Diario del Capitán de Fragata Juan Francisco de Aguirre", Revista de la Biblioteca Nacional, T. XX, n. ${ }^{\circ}$ 47-48, Buenos Aires, 1950, pp. 9-598.

Marc Augé: Hacia una antropología de los mundos contemporáneos. Barcelona, Gedisa, 1998 (1994).

82 AGNA, Sala IX, 10-6-3. Inventario de la residencia jesuítica de Belén. Buenos Aires, 1768. “(...) y abriendo dicho Señor Sargento Mayor el Aposento del Padre Joseph Quiroga se halló lo siguiente: primeramente nueve tomos en cuarto en pergamino Tosca de Matemáticas (...); un tomo en folio en pergamino Don Jorge Juan Observaciones Astronómicas del Perú; un tomo en octavo en pasta Bouguer de navegaciones en francés; un tomo en cuarto en pasta óptica de Neuton (Newton); un tomo en cuarto en pasta tablas astronómicas de Munciux de la Hire; un tomo en cuarto en pasta Tratado de la Navegación por el Señor Bouguer en francés; un tomo en octavo en pergamino de tablas tangentes y secantes (...); un atado de diferentes mapas manuscritos e impresos y otros papeles y cartas".

83 AGNA, Sala IX, Legajo 6-10-5. Santa Catalina, 20 de enero de 1762.

84 AGNA, Sala IX, 17-8-5. Santa María la Mayor, 7 de diciembre de 1787. Firmante Francisco Bruno de Zabala. 
Félix de Azara: "Geografía física y esférica de las Provincias del Paraguay y Misiones Guaraníes", Anales del Museo Nacional, Sección Historia y Filosofía, T. I, Montevideo, 1904, pp. 1-467.

Graciela Chamorro: Kurusu Ne ëngatu, palabras que la historia no podría olvidar, Asunción, Universidad Católica, 1995.

- Teología Guaraní, Quito, Abya-Yala, 2004.

- "Ciclo de vida en los pueblos guaraní. Aporte lingüístico a partir de los léxicos de Antonio Ruiz de Montoya", Suplemento Antropológico, V. XLII, n. ${ }^{\circ}$ 1, Asunción, junio de 2007, pp. 7-56.

Miguel Chase-Sardi: "Ligeras notas sobre la prehistoria de los Arawak, Karibe y Tupí-Guaranî”, Suplemento Antropológico, V. XXVII, n. ${ }^{\circ}$ 2, Asunción, diciembre 1992, pp. 7-30.

Jaime Cortesao (Int. e Notas): Manuscritos da Coleçao De Angelis. Jesuitas e Bandeirantes no Tape (1615-1641), Río de Janeiro, Biblioteca Nacional, 1969.

Manuela Carneiro da Cunha y Eduardo Viveiros de Castro: "Vinganca e temporalidade: os tupinambá", Anuario Antropológico, n. 85, Río de Janeiro, 1986, pp. 57-77.

Guillermo Furlong: Cartografía jesuítica del Río de la Plata, Buenos Aires, Peuser, 1936.

- Matemáticos argentinos durante la dominación hispánica, Buenos Aires, Editorial Huarpes, 1945.

- Joaquín Camaño SJ y su Noticia del Gran Chaco, Buenos Aires, Librería del Plata, 1955.

- Juan de Escandón SJ y su carta a Burriel, Buenos Aires, Ediciones Teoría, 1965.

Julio César González: "Contribución al conocimiento de la cartografía colonial”, Boletín del Instituto de Investigaciones Históricas, n. ${ }^{\circ} \mathrm{XXIV}$, Buenos Aires, 1940, pp. 58-81.

- Don Félix de Azara, Buenos Aires, Editorial Bajel, 1943.

Norberto Levinton: "Las estancias de Nuestra Señora de los Reyes de Yapeyú: tenencia de la tierra por uso cotidiano, acuerdo interétnico y derecho natural (Misiones Jesuíticas del Paraguay)", Revista Complutense de Historia de América, V. 31, Madrid, 2005, pp. 33-51.

- La arquitectura jesuítico-guaraní. Una experiencia de interacción cultural, Buenos Aires, Editorial SB, 2008.

- San Ignacio Miní: la identidad arquitectónica, Buenos Aires, Contratiempo Ediciones, 2009.

- El espacio jesuítico-guaraní, la formación de una región cultural, Asunción, CEADUC, 2009.

Ernesto J. A. Maeder (int.): Cartas Anuas de la Provincia del Paraguay 16371639, Buenos Aires, FECIC, 1984. 
- "La población de las Misiones de Guaraníes (1641-1682). Reubicación de los pueblos y consecuencias demográficas", Estudos Ibero-americanos, V. XV, n. ${ }^{\circ}$ 1, Porto Alegre, 1989, pp. 49-68.

- (int.): Cartas Anuas de la Provincia Jesuítica del Paraguay 1641 a 1643, Resistencia, Instituto de Investigaciones Geohistóricas, 1996.

- (int.): Cartas Anuas de la Provincia Jesuítica del Paraguay 1644, Resistencia, Instituto de Investigaciones Geohistóricas, 2000.

Bartomeu Meliá: "Potyró: las formas de trabajo entre los Guaraní antiguos "reducidos" y "modernos", Revista Complutense de Historia de América, n. ${ }^{\circ} 22$, Madrid, 1996, pp. 183-208.

Martín María Morales, SJ (comp. e int.): A mis manos han llegado. Cartas de los PP Generales a la Antigua Provincia del Paraguay (1608-1639), MadridRoma, Universidad Pontificia de Comillas/Institutum Historicum Societatis Iesu, 2005, vol.1, pp. 1-68.

Fernando María Moreno, SJ; Rafael Carbonell de Masy, SJ; Tomás Rodríguez Miranda, SJ (int.): Para que los indios sean libres...Escritos de los mártires de las Reducciones guaraníes. Asunción, Colección Santos Mártires, 1994.

Louis Necker: Indios guaranís y chamanes franciscanos. Las primeras reducciones del Paraguay (1580-1800), Asunción, Universidad Católica, 1990.

Marshall Sahlins: Islas de historia. La muerte del capitán Cook. Metáfora, antropología e historia, Barcelona, Gedisa, 1988 (1985).

Helio Vianna (int. e notas): Jesuítas e Bandeirantes no Uruguai (1611-1758), Río de Janeiro, Biblioteca Nacional, 1970. 
Apéndice: Cartografía

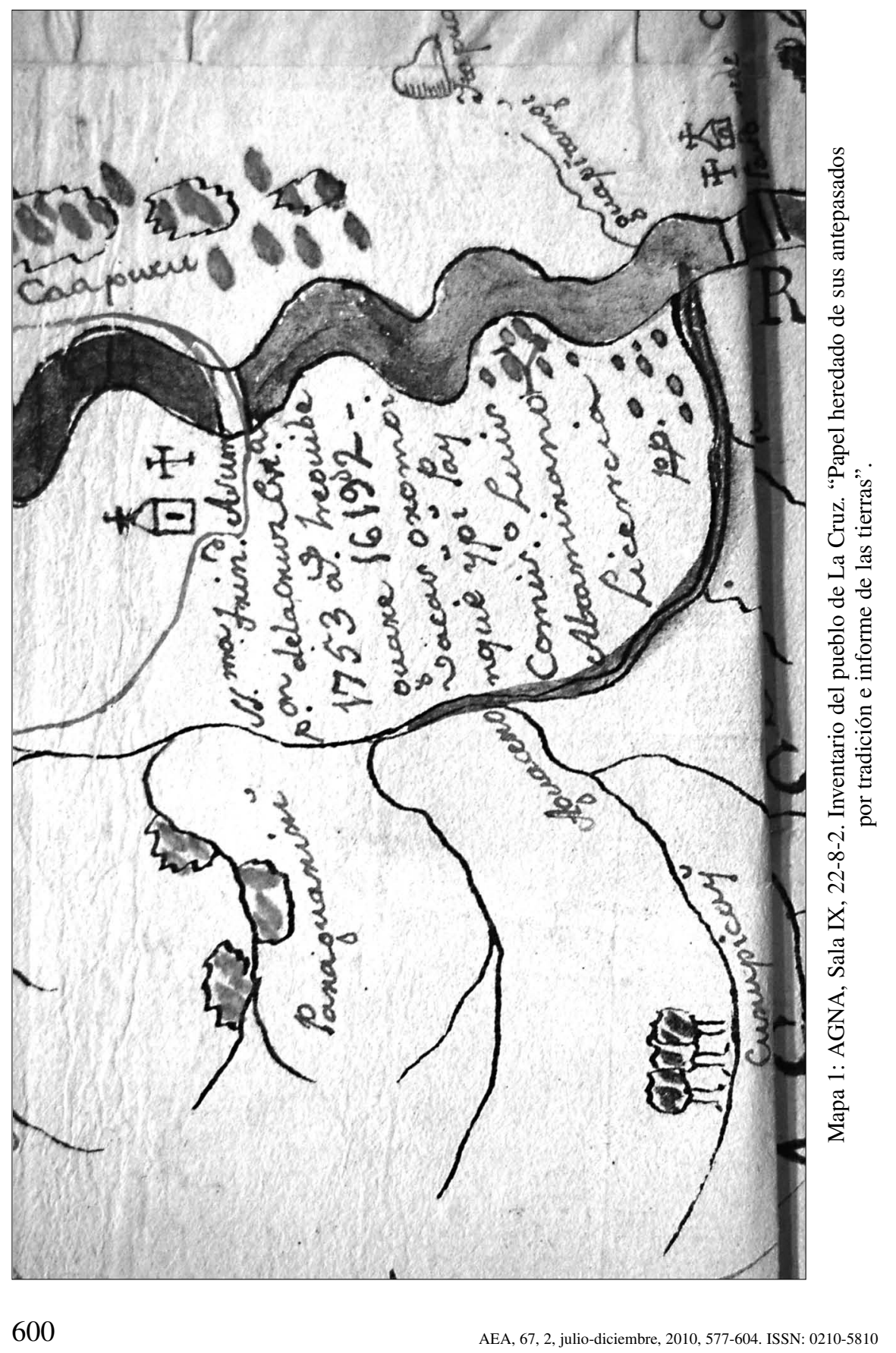


LA MICRO-REGIÓN: LA CARTOGRAFÍA POR LA INTERACCIÓN JESUÍTICO-GUARANÍ

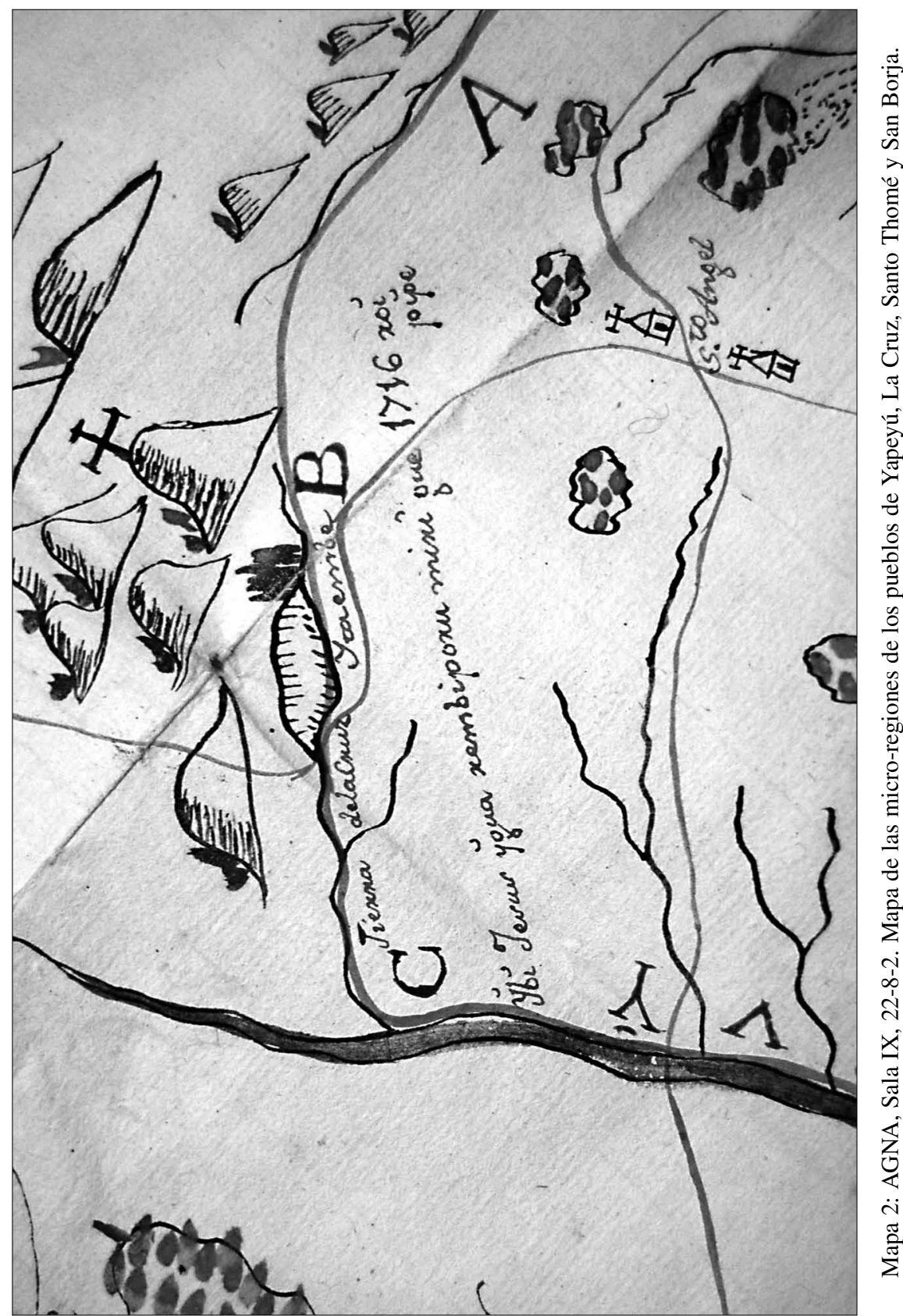


NORBERTO LEVINTON

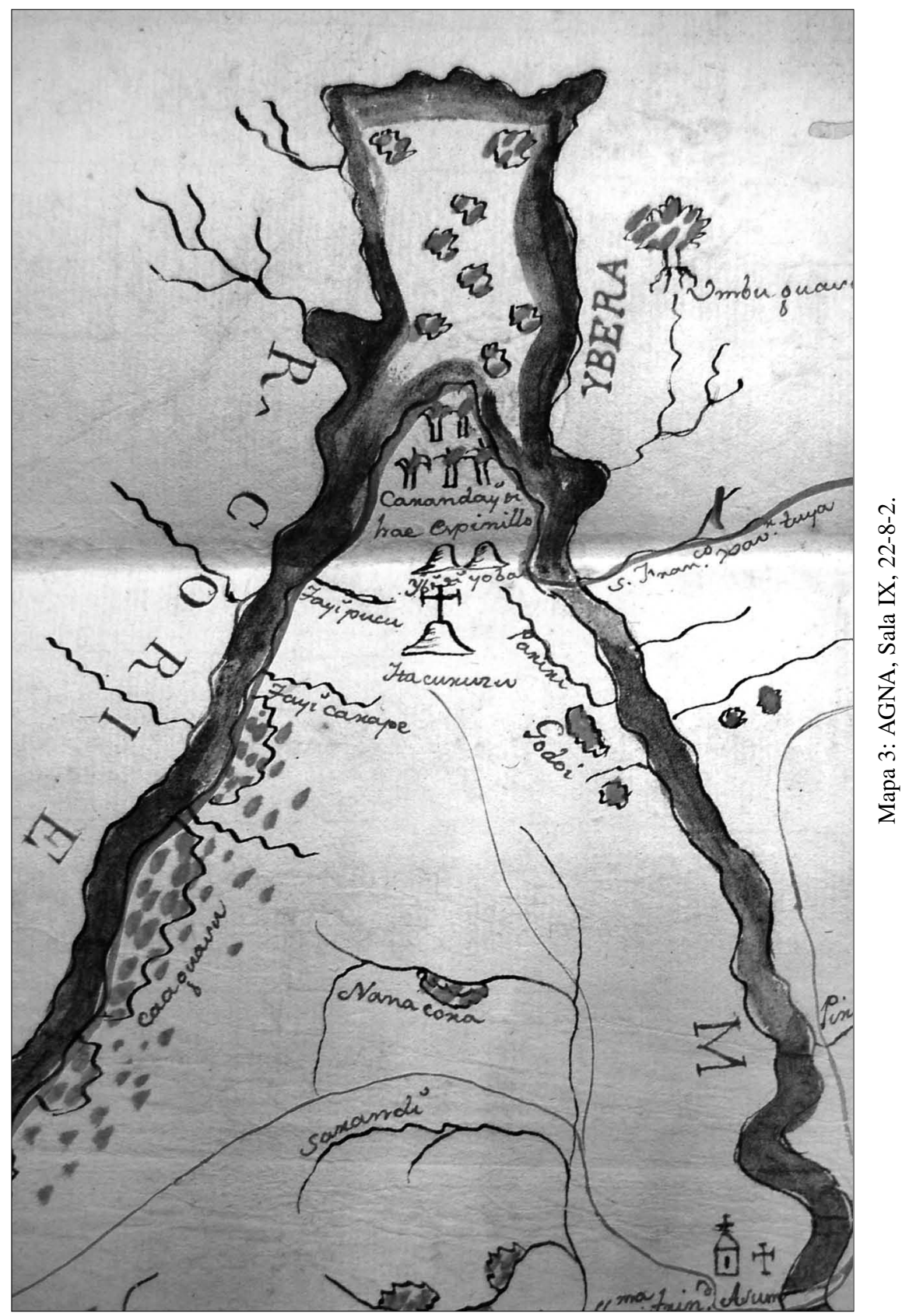


LA MICRO-REGIÓN: LA CARTOGRAFÍA POR LA INTERACCIÓN JESUÍTICO-GUARANÍ

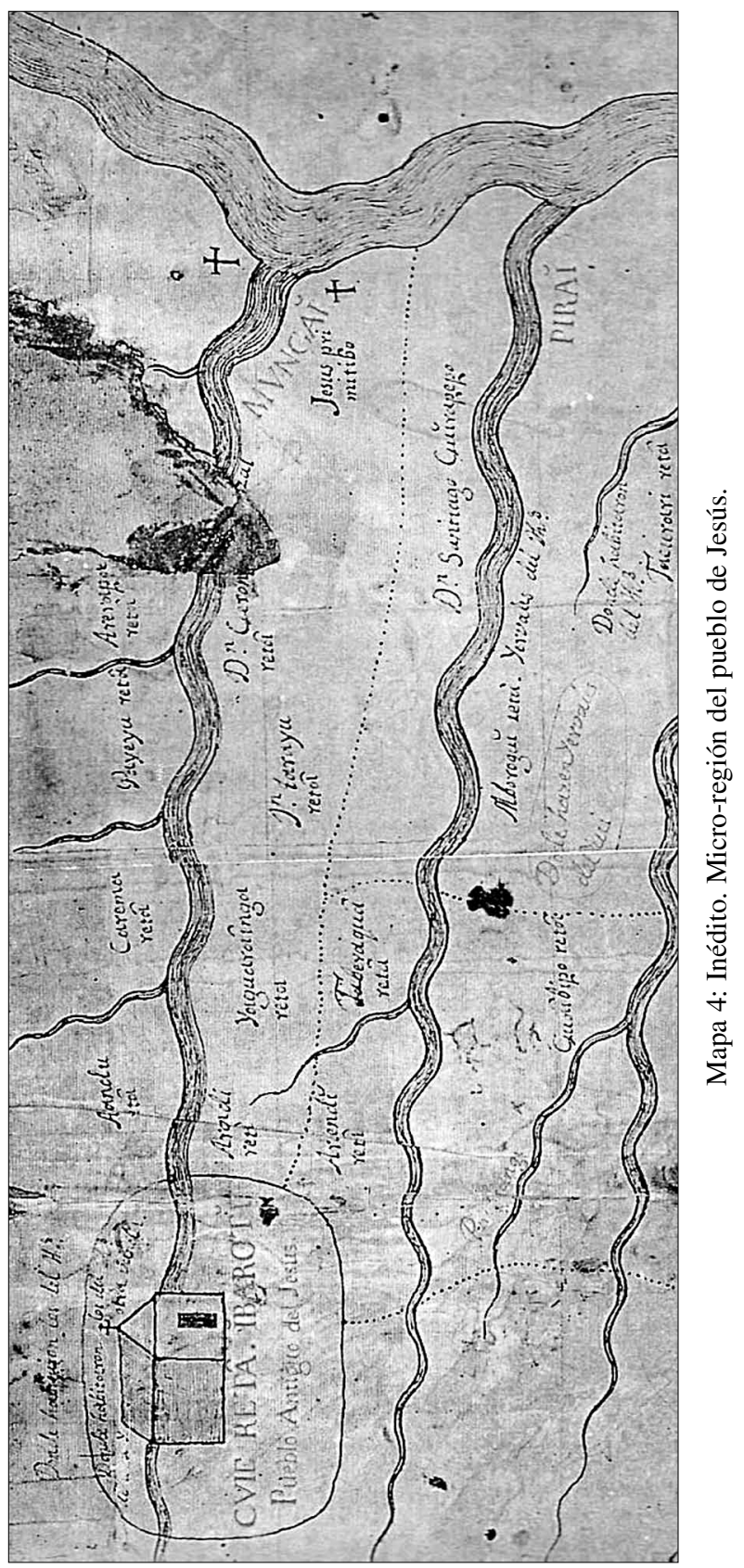


NORBERTO LEVINTON

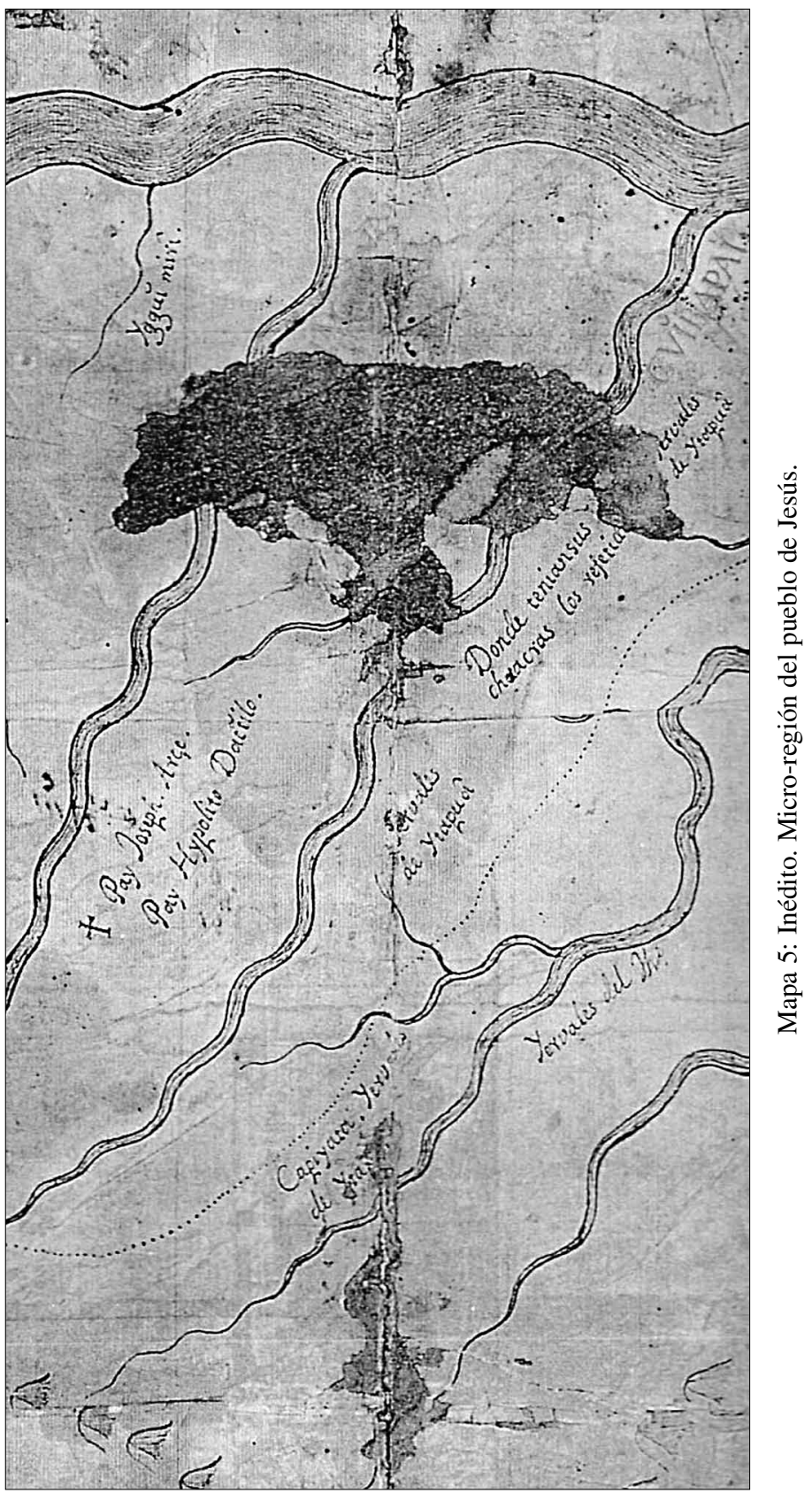

